\title{
Shoes for the Shoemaker's Children: Providing an Accreditation Process for Programs Offered by Educational Developers
}

Celia Popovic, Mandy Frake Mistak, Alison Jeppesen, Cynthia Korpan, Suzanne Sheffield, and Mark Weyers York University, University of Victoria, Red Deer College, Dalhousie University, Western University

DOI: $10.22329 /$ celt.v11i0.4964

Educational developers in universities and colleges design, develop, and deliver courses and programs for professors and teaching assistants (TAs) to support teaching and learning in postsecondary institutions. These courses and programs, however, are often not accredited, so the Educational Developers Caucus (EDC) created a working group to explore the appetite for a Canadian accreditation process, and then design and implement a framework. This article summarizes the working group's outcomes, and reports on an initial evaluation of their impact, arguing for their contribution to enhancing the quality of faculty and TA development courses and programs and, thereby, of teaching and learning.

Les concepteurs de contenus pédagogiques dans les universités et les collèges conçoivent, élaborent et offrent des cours et des programmes pour les professeurs et les auxiliaires d'enseignement afin de soutenir les activités d'enseignement et d'apprentissage dans les établissements postsecondaires. Cependant, bien souvent, ces cours et ces programmes ne sont pas certifiés. Aussi le Caucus des concepteurs de contenus pédagogiques a-t-il créé un groupe de travail pour explorer la possibilité d'un processus de certification, puis pour concevoir et mettre en ouvre le cadre d'un tel processus. Cet article présente le résumé des résultats $d u$ groupe de travail et une évaluation initiale des répercussions, tout en arguant que ces résultats contribueraient à améliorer la qualité des cours et des programmes élaborés par les professeurs et les auxiliaires d'enseignement et, par suite, la qualité de l'enseignement et de l'apprentissage.

$\mathrm{I}$

n 2014 the Executive of the Educational Developers' Caucus (EDC), a constituency of the Society for Teaching and Learning in Higher
Education (STLHE), formed a working group to examine the feasibility of implementing an accreditation process for educational development 
programs in Canada. These programs are formal professional development activities that range from single workshops (or a series of workshops) to full courses that are part of a traditional academic program. The working group investigated the current situation in Canada and other forms of accreditation available internationally to identify the advantages and disadvantages of accreditation, to ascertain what a Canadian accreditation process might look like, and to determine whether the EDC would be an appropriate body to institute such a system.

During the consultation period of two years, the need or value of an accreditation process was hotly contested. The benefits of engaging in accreditation were seen as providing rigour to our practices, enabling us to defend their legitimacy within and beyond our institutions if needed. Ultimately, it was felt that if the EDC did not undertake this role, and the need was agreed, then another body (or bodies) would do so. For example, in the US, the American Association of Colleges of Pharmacy noted that due to "a lack of outcomes-orientated facultydevelopment programs in colleges and schools of pharmacy" (Guglielmo, Edwards, Franks, Naughton, Schonder, Stamm, Thornton, \& Popovich, 2011, p. 1) that it may make sense for them to "endorse" faculty development programs and work to develop a best-practice model "toward the creation of the optimal faculty development program" whose outcomes could be evaluated on a regular basis (Guglielmo et al p. 9).

Following consultation with the Canadian educational development community, an accreditation process and framework was devised. Thereafter, several members of the working group took a program from their own institution through the newly devised process to pilot both the process and the framework. In this paper, we briefly outline the consultation process, how the framework was developed and report on an early evaluation of the process while highlighting the potentially positive impact on the quality of program/course design.

\section{International Forms of Accreditation}

Accreditation frameworks vary from discipline to discipline. In general, there are several common elements in program accreditation. The Institute of Medicine (US) Committee on Assessing the System for Protecting Human Research Subjects (2001) suggests the following elements of program accreditation: that the accreditation organization be a national body that can facilitate the overall accreditation process; that there should be an application process with set criteria; that there is a process of self-evaluation; that there be an external evaluation that includes site visits by external accreditors; that there be process for appeals; that the cycle of self-evaluation and external evaluation be repeated; and that there be a set of measurable standards.

There is a dearth of literature on accreditation of professional development programs. We reviewed a number of international and national frameworks and accreditation programs. Currently the UK and Sweden have national accreditation systems and Lebanon is in the process of developing a professional standards framework for teaching in higher education. Aside from these examples we were unable to find any accreditation systems specifically designed for courses and programs of professional development for faculty and teaching assistants (TAs).

\section{United Kingdom}

The most widely known external accreditor for faculty development programs, both in the UK and internationally, is the Staff and Educational Development Association (SEDA). SEDA is an organization that works directly with educational developers while the Higher Education Academy 
(HEA), another potential source of course accreditation, has led to the establishment of the UK Professional Standards Framework (UK-PSF). The UK-PSF goes past the simple accreditation of courses to provide a framework that sets standards for individuals teaching in higher education. The framework tends to be aligned with promotional frameworks within UK universities, and grants fellowships to those who have successfully met the standards of HEA accredited courses. Another national framework, developed by the Academy of Medical Educators (AoME), has also been created and aligned to the UK-PSF. AoME is a multiprofessional organisation for all those involved in the education and training of students and practitioners in medicine, dentistry and veterinary science.

Prior to the project outlined in this paper, the SEDA process was the only means of program accreditation. Other processes described herein relate to the accreditation of individual TAs or professors who complete specified programs.

\section{Sweden}

In Sweden faculty are required to undergo mandatory pedagogical training. University rectors (senior administrators) reached a consensus for a common core for the content of the training, based on proposals from Lund University, which were in turn, based on their successful track record of program delivery. While accreditation is not an aspect of the current system, the compulsory nature and move towards a national framework justifies it for inclusion here (Norway and Denmark also have mandatory training). Martensson, Roxa, and Olsson (2011) describe the move from high participation rate pedagogical courses to mandatory programs in Sweden in 2003. The learning outcomes for the mandatory programs were based on the Scholarship of Teaching and Learning (see Lindberg-Sand and
Sonesson (2008) for an account of this process and of the suggested learning outcomes).

\section{Lebanon}

The E-TALEB project, now in its final year, was initiated in January 2016 to establish a Professional Standards Framework for Excellence in Teaching and Learning (LBPSF) in Lebanese universities. The project is being led by the Holy Spirit University of Kaslik (USEK) with several European partners (from UK, Denmark, Germany and France) in addition to several Lebanese universities. It was identified that developing human capital and teaching talent in the region is becoming increasingly important to sustain the competitiveness of Lebanese higher education. Therefore, the goal of the project is to support the initial and continuing professional development of staff engaged in teaching and to foster dynamic approaches to teaching and learning through creativity, innovation, and continuous development. The LBPSF was finalised in 2017 and has been endorsed by the Ministry of Higher Education with the purpose of enabling innovation and the exchange of good practice through Centres of Excellence in Learning and Teaching in Higher Education and through a national certificate in Learning and Teaching in Higher Education.

\section{Other Forms of Accreditation}

In terms of less traditional forms of institutional recognition, a few institutions in the United States have implemented digital badges to recognize and incentivize participation. See, for example, Indiana University's Center for Innovative Teaching and Learning (https://citl.indiana.edu/), and Texas Wesleyan University's Centre for Excellence in Teaching and Learning (http://txwescetl.com/). In Canada, McGill's "Skillsets" program is jointly offered through the Teaching and Learning Centre 
and Graduate and Postdoctoral Studies. To date, there does not appear to be any similar national schemes available in the US, Australia, or elsewhere.

\section{The Canadian Context}

Prior to this EDC project there was no Canadian accreditation process for faculty development programs. There were and are some parallel processes for specific areas, such as the Canadian Society for Training and Development (CSTD) which offers accreditation for members who have completed their program or programs that they recognize. These include adult education programs offered by Canadian colleges and universities. A survey of Educational Development Centres (under the titles of Academic Development Offices/Centres or Centres for Teaching and Learning and various other titles) reveals, as in many other countries, a vast array of programming options in Canada for faculty and graduate students. In the absence of a formal, national accreditation body for professional development programs in educational development, recognition of program completion has been achieved from a variety of sources ranging from "highly formalized recognition" (such as an institutionally approved certificate or SEDA Certification) to "less formalized recognition" (such as a centre-approved certificate or a co-curricular/transcript notation) with more institutions offering the less formalized recognition and fewer offering external recognition (Kenny, Watson, \& Watton, 2014, pp. 12-13). We note a subtle, but important, difference between accreditation and recognition. While both imply an oversight of program design, delivery and evaluation, accreditation has the added meaning of accountability and measurement of standards by an external professional body. Recognition, in contrast, is taken to mean an assessment of the quality and rigour involved in a program offered by an educational development centre. It is the program itself that is scrutinized, rather than the achievement of participants in the program.

The range of recognition includes: international accreditation through SEDA, provincial recognition, institutional recognition, both senate approved designations and notations on transcripts, co-curricular transcripts and/or tenure and promotion documents, and recognition from faculties of Education and/or teaching and learning centres. Some programs have sought recognition from multiple sources, resulting in programs that may be simultaneously accredited by SEDA, the institution's senate, and the teaching and learning centre, for example.

Of the forms of recognition currently available in Canada, certification from the Teaching and Learning Centre itself is a very common method for both graduate student and faculty teaching development programs. These certificates vary in duration, requirements and audience. Some programs, like the University of Manitoba's Teaching and Learning Certificate claim to provide enhanced tenure prospects, while similar programs at the University of Regina and at Cape Breton University offer more intrinsic motivators like "mak[ing] teaching/learning more enjoyable for you and your students" ("University Teaching Program," n.d.).

\section{An Accreditation Process in Canada}

In historical and practical ways, it made perfect sense for our community of practice to organize and sustain a credible and professional accreditation system for the programming that our members, largely, deliver. We found compelling the suggestion that if we did not come up with a way to accredit educational development programs, some other body invariably would, and may have attempted to accredit or discredit such programming with perhaps something other than the theory and practice of educational 
development in mind. Such a danger may explain why some of our institutions had already looked abroad to fill a need with, simultaneously, the rigour and supportive ethic of care to which educational development aspires (SEDA accreditation). Many felt that a home-grown, equally robust, model would be preferable to seeking approval overseas.

The EDC is the professional body for educational developers in Canada, run by and for our community. It identifies itself as a community of practice to "...facilitate the advancement and evolution of educational development as a field of practice and scholarship by communications, networking, professional development opportunities and advocacy strategies" (About the EDC, n.d., para $1)$.

Financially speaking, the lack of a funded office with support staff in the EDC was a potential barrier, as, unlike SEDA, the EDC does not have an infrastructure that could be responsible for managing payments, issuing certificates and maintaining records. However, the lack of this organizational infrastructure was also deemed an advantage since the high cost of SEDA accreditation was perceived as a barrier by many. In meeting the challenge posed by a lack of infrastructure we were also able to address the issue of fees and keep costs to the EDC to a minimum.

The benefits identified in the original discussion paper were:

1) Development of consistent, high quality programing across Canada while maintaining flexibility to meet institutional and geographical contexts;

2) Profile and visibility for educational development and EDC in Canadian higher education;

3) Institutional profile in support of excellence in teaching and learning;

4) Enhance student learning by enhancing the professional development of teaching;
5) Provide early career and T\&P faculty with Canada-wide recognized credential, which may eventually have a positive impact on hiring/T\&P;

6) Overview of teaching expectations for public/participants/employers;

7) An opportunity for educational developers and our Centres to get feedback on our work, drive change, and raise the profile of teaching / learning;

8) Allow for collection of impact data within and across institutions;

9) Accreditation cycles could help us to assess the quality, and possibly impact, of a significant portion of our work both locally and in the service of potential SoTL research;

10) Mapped appropriately to existing professional accreditation systems, an EDC system could increase visibility and add uptake for development activities.

The disadvantages and challenges were identified as:

1) Uncertainty about the perceived and/or real need for accreditation of programs;

2) Uneven resourcing of institutions and teaching and learning centres that may impact ability to staff and fund accreditation process and accredited programs;

3) Risk of stifling program creativity, innovation or local specificity in an effort to align with or conform to accreditation requirements;

4) Risk of counting and measuring more than simply doing our work, and all that this entails for local centres as well as for our national executive;

5) Ethical challenges of ensuring equity and transparency of accreditation processes within a relatively small educational development community; 
6) Changes to the nature of EDC's core mission and aims, for better or for worse.

\section{What We Did}

The EDC Working Group published a discussion paper (Winnipeg, 2015), which formed the basis for a consultation process with EDC members. The conclusion of the consultation was that some form of accreditation would be welcomed by the community but with an array of conditions to make it acceptable in the Canadian context. The EDC Executive tasked the Working Group with creating a draft framework. This framework addressed concerns raised during the consultation period, was tested on several programs, presented to the EDC community through a webinar (May 2016), and approved by the EDC Executive (June 2016).

The Working Group sought to establish a framework that would be rigorous while simultaneously providing flexibility for the variety of programs and courses offered by different teaching and learning centres. There were key aspects of quality teaching and learning that members of the EDC tend to agree upon and that subsequently course/program participants would recognize as valuable regardless of varying contexts and needs. There were already existing frameworks, such as the TA Competencies Framework created by the Teaching Assistant Graduate Student Advancement (TAGSA) group, a special interest group (SIG) of STLHE, to frame the skills and development needed for TAs (as opposed to future faculty) (Korpan, Sheffield, \& Verwood, 2015). Yet institutional and geographical context and disciplinary differences were relevant considerations, so the accreditation framework required the flexibility to allow for a specific institution to mould and adapt foundational guidelines to the needs of their context. The Working Group was mindful about avoiding the creation of a framework that stifled innovation while emphasizing the benefit of inter-institutional, collegial support and development.

In creating the framework, the Working Group established criteria that would establish if courses/programs were supporting the teaching development of faculty over time. Additionally, there was a request for curriculum data that would include the outcomes/objectives of the course/program and the methods of assessment.

\section{Disadvantages and Community Concerns of Accreditation}

Several disadvantages of accreditation, identified in the original discussion paper and through feedback, were addressed in the creation of the framework. Uncertainty about the perceived and/or real need for accreditation of programs and (potential) changes to the nature of EDC's core mission and aims are two such examples. Resources and cost emerged as one of the most troublesome disadvantages of accreditation. We were aware of the differences in allocation of financial resources and the difference in human resources among institutions. While many institutions have established teaching and learning centres with dedicated staff and rich histories of robust programming, many other institutions do not. Moreover, the documented trend in the frequent restructuring of teaching and learning centres means that programming direction is subject to unpredictable change (Grabove, Kustra, Lopes, Potter, Wiggers \& Woodhouse, 2012). We addressed this by devising a self-sustaining model in which those reviewed become reviewers. We were concerned that accreditation could unfairly disadvantage teaching and learning centres without the financial or human resources to pursue accreditation. We believe our model addresses this issue.

A concern emerged during the consultation regarding the temptation to shape program decisions 
based on the likelihood or possibility of receiving accreditation. The framework was designed to ensure rigour, while simultaneously allowing flexibility. Because of the flexible design of the framework, we were able to remove the risk of counting and measuring, and all that this entails for local centres as well as for our national executive in the EDC.

Lastly, a concern regarding the ethical challenges of ensuring equity and transparency of accreditation processes within a relatively small educational development community was raised. We have taken measures to respond to this concern. Namely, this process is a voluntary one. There is no requirement either by the EDC, the Working Group, or any institution to date that any course or program be accredited. We have published the framework, its criteria, and the names of the Working Group, (who are also reviewers), on the EDC website. This is publicly available information so that informed decisions can be made as to whether to seek accreditation for a course or program. Finally, and perhaps most importantly, this is a peer-based process. Reviewer's names are shared openly with applicants; applicants and reviewers meet either faceto-face or online during the process itself where they engage in open-dialogue. In turn, applicants who sought accreditation can become reviewers themselves and are supported by existing members of the Working Group.

\section{Founding Principles}

Having shared the discussion document with the Canadian EDC community and gathered feedback, the working group decided on several founding principles that, ultimately, would guide the accreditation process.

The first, and perhaps most critical, of our founding principles is that we accredit programs not people. The consensus was that a framework was required to address programs (workshops, courses) offered to faculty and TAs rather than provide accreditation for participants of those programs. Thus, the framework is designed to ensure the rigour of a program. An accredited program provider may put the EDC logo onto their certificates, but EDC themselves do not issue certificates to participants, only to the program provider.

A key objection to the SEDA recognition process was the expense of having a course accredited. This was considered prohibitive for many centres. The working group designed a process that relies on the voluntary contributions of the community rather than a financial transaction. This avoids the need for accounting processes. While voluntary work is not 'free' this approach seemed to be a good fit for the Canadian context. The process must be of low cost and sustainable, by which we mean it is not dependent on the original working group for its continued existence. The review process was designed with this in mind.

The Working Group is determined to ensure rigour but avoid unnecessary bureaucracy. The community was clear that they would value a process that was simple but rigorous and which would entail a minimum amount of paperwork. The main driver on this seemed to come from comparison with other accreditation processes where the balance was perceived to be undesirable.

The consensus was that any pan-Canadian accreditation framework required flexibility to address institutional and provincial differences. The framework was developed to allow teaching and learning centres to seek accreditation while respecting the diversity of centre and program/course types.

\section{EDC Accreditation Framework - The Process}

In his discussion of how quality teaching "transforms students' perceptions of their world," Biggs (2001) also argues that it "transforms teachers' conceptions 
of their role as teacher" (p. 222). In the context of 'quality enhancement', he believes staff development should play an institutional role rather than only focusing on the individual teacher. Thus, in thinking about the advantages of accreditation, the Working Group considered the impact of such a process on faculty and future faculty's teaching, the impact on student learning, and the impact on educational developers' practice. It has been argued that faculty and graduate student development programs, that introduce 'best practices' in teaching and learning can enhance their students' learning experience, engagement and ultimately academic success. Ideally, accrediting such programs would further enhance them via a peer review process and, in turn, play an important role in supporting learners in higher education. In this way, faculty development programs should be making "strategic contributions" to institutions that are increasingly emphasizing retention and the importance of the student experience (Holt, Palmer and Challis, 2011, p. 5). The framework itself requires an applicant to address the following criteria:

- appropriate, up to date, evidence informed materials used in the course (content);

- clearly defined course learning outcomes aligned with assessment methods and instructional activities;

- application of evidence-based practice;

- active engagement by participants;

- appropriateness of the program's format and structure;

- methods used to assess candidate achievement;

- a system to enable continuous improvement of the program;

- management and accountability structures of the provider;

- commitment of the provider to continuous improvement and quality assurance; and

- institutional support and resources, including release time and any constraints for the program and participants engaging in the program.

Following submission, the application is assigned to two reviewers who review and discuss the application before meeting (online or in-person) with the applicant for clarification (if needed or desired). The decision is then communicated to the EDC Accreditation Committee, which reviews it. Following successful accreditation, the applicant is mentored to be a reviewer for two future reviews. Throughout the process, a collegial system of peersupport and development is enacted to meet the Aims of the Accreditation Framework:

...to provide a means to ensure high quality provision of Continuing Professional Development (CPD) programs at Canadian post-secondary institutions. It is designed to be flexible enough to be used with any program, yet structured to provide a consistency of approach such that any program accredited by EDC may be assumed to have met EDC values of open community, collaboration, ethical practice, and scholarly approach. This is not accreditation of individuals who participate in programs (Accreditation: Programs accredited by the EDC (n.d.).

The framework enables the EDC to take a leadership role in ensuring development of programming of a consistently high quality across Canadian institutions. This role enhances the profile and visibility of educational development as a profession and the EDC as a professional body. It has the potential to provide consistency in the accrediting process across Canada if adopted by all.

\section{Evaluation of the Initial Process}

To assess the framework, the authors conducted a small evaluative research project asking questions connected to the multiple roles each author had as a 
member of the Accreditation Committee: as someone seeking accreditation; and as someone reviewing other applications. The purpose of this qualitative, reflective study (with Ethics Approval) was to evaluate the process from these multiple perspectives. Each member of the Accreditation Committee was asked the following in a written survey format:

\section{Perspective of someone seeking accreditation:}

1) What was your initial motivation to engage in this process?

2) Did your motivation change during the process, if so how and why?

3) Aside from completing the process to gain accreditation what did you find useful or challenging in the process (for example, completing the documentation or attending meetings)?

4) As you completed the framework document did you regard the process as an opportunity to seek advice and feedback, or did you regard it as a test?

\section{Perspective of a reviewer:}

1) What did you find most interesting, rewarding, engaging as a reviewer for the EDC accreditation?

2) What did you find most challenging, frustrating, annoying, as a reviewer for the EDC accreditation?

\section{Perspective of a committee member:}

1) Thinking back over the process involved in creating the EDC accreditation system, what were the key challenges and opportunities?

2) Were there any key issues that emerged in the process that changed the outcome compared to what you expected at the outset?

Once the responses were collected, they were coded and themed using a textual analysis process (Creswell, 2002; Patton, 2002). We discuss the preliminary results in the following section.

\section{Emergent Themes}

Having reviewed and coded participant responses, there was an overwhelmingly positive response regarding the accreditation process and the framework that has been developed. For example, numerous participants indicated their motivation to take part was driven by a desire to gain credibility both internally within an institution, and externally within the wider postsecondary education community. A few participants felt that having an EDC accreditation would help to raise the profile of educational development in general and of the EDC specifically. Of note, in the initial implementation phase, the Accreditation Committee rejected one application as it did not meet the minimum requirements of connected series of events (learning opportunities, course, workshops, etc.) with an assessment of learning. The framework, thus, provides a means of achieving a benchmark across the sector. Moreover, participants shared that engaging in the review process helped a course provider at one institution to understand where their program fits compared with those on offer at other institutions.

The accreditation process was designed to encourage reflection and self-assessment. This process encourages ongoing professional development which was identified by numerous participants as a positive opportunity both as a program provider and as a reviewer. Similarly, the accreditation process provides the opportunity for continuous improvement. Participants stated that feedback from reviewers enabled the course provider to improve their program offering(s), identify gaps, and highlight strengths, that would help ensure that the program is rigorous and of high quality.

The responses from participants indicated several key motivations for seeking accreditation. Key motivations for seeking accreditation were: credibility and quality; sharing of ideas; shaping of course development; and having Canadian accreditation. For most participants, these motivating factors did 
not change during the accreditation process. For some, there was increased motivation during the process as they more clearly recognized the value of the developmental approach of the process and the increased need to thoughtfully engage in examining their course/program as part of the accreditation process. A limitation was that many participants, having not sought accreditation elsewhere, had no basis for comparison to other accreditation processes. This may be an area of future research.

As reviewers, the key benefits were connected to learning, having a sense of community, and gaining new insights into resourcing and priorities at other institutions. It is not surprising that a group of educational developers identified 'learning' as one of the key benefits. Respondents valued learning about other programs, discovering how others perceive development of programs for various groups, and exploring how priorities differed across institutions. As with many EDC initiatives, one of the key benefits was the professional connections and growth opportunities that this process provided to participants. Challenges as a reviewer centred on the documentation as some sections were challenging or repetitive.

As committee members, the key challenges and opportunities were identified as whether the committee accredits people or programs: the diversity of teaching and learning centres and their respective programs; the work involved in being a committee member; piloting the framework in the winter of 2016; and the mapping of the outcomes template. As previously mentioned, a key challenge for the initial group was separating out the accreditation of programs from the accreditation of people (either educational developers or program participants). Since Canada is vast with decentralized postsecondary and numerous models of institutions, centres, and programs, part of the challenge was making sense of this Canadian context and developing a framework that supported this diversity. The multiple perspectives of the committee members made the framework stronger despite the challenges of working through online synchronous meetings and asynchronous group work. Throughout the process, the Working Group benefitted from decision making through consensus. Piloting the framework in 2016 with nine (9) programs (a mix of graduate student/teaching assistant and faculty programs) was valuable to addressing issues within the framework and the documentation through the process of both approving and denying accreditation. It also allowed the committee to consolidate some criteria around the nature of a course or program that would seek accreditation. This was a collaborative learning process that led to a stronger accreditation framework. A key outcome of the pilot was the development of a mapping template enabling programs to illustrate their curricular alignment in an easy-to-read format.

\section{Conclusion}

A small working group started in 2014 to explore the role of the EDC in the possibility of a Canadian accreditation model for teaching development programs offered by teaching and learning centres, has evolved into a full EDC Accreditation Committee with a carefully constructed, self-sustaining accreditation process. This voluntary accreditation process serves a need in the Canadian context and provides those seeking accreditation, or those seeking to design a program/course, with a supportive and mentoring system and group of peers.

Accreditation provides educational developers themselves with opportunities to give and receive peer-review of courses/programs crossinstitutionally to enhance program creation, development, and review, and ensures that programs/courses continue to be timely and relevant. Ideally, such a peer review process stimulates innovation through conversation, allows for shared 
ideas and implementation thereof, and produces qualitative peer review that provides feedback in context. Moreover, it enables educational development collaborations across institutions.

As the accreditation framework builds traction at universities and colleges across Canada, and possibly beyond, we intend to conduct further research into the efficacy and value of the process. We expect to fine-tune the reviewing process and to identify whether the requirement to review causes any issues for colleagues, particularly those in small centres. The evaluative research will include stakeholders such as senior administration and program participants, as well as program leads.

Time will tell whether this accreditation process meets the needs of educational developers in Canada, and if we have succeeded in responding to the context of developers in this country. Perhaps more significantly, we will discover whether we have achieved our aim of meeting the ever-increasing needs of institutions to provide accredited programs and to have them formally recognized/approved by professional bodies or outside organizations.

\section{References}

About the EDC (n.d.). Retrieved from: https://www.stlhe.ca/affiliatedgroups/educational-developerscaucus/about-the-edc/

Accreditation: Programs accredited by the EDC (n.d.). Retrieved from https://www.stlhe.ca/affiliatedgroups/educational-developerscaucus/accreditation-for-courses-orprograms/

Biggs, J. (2001). The reflective institution: Assuring and enhancing quality of teaching and learning. Higher Education, 41, 221-238.
Creswell, J. (2002). Educational research: Planning, conducting, and evaluating quantitative and qualitative research. Upper Saddle River, NJ: Pearson Education, Inc.

Grabove, V., Kustra, E., Lopes, V., Potter, M., Wiggers, R., \& Woodhouse, R. (2012). Teaching and learning centres: Their evolving role within Ontario colleges and universities. Toronto: Higher Education Quality Council of Ontario. Retrieved from: http://www.heqco.ca/SiteCollectionDocum ents/TL\%20Centres\%20ENG.pdf

Guglielmo, J., Edwards, D., Franks, A., Naughton, C., Schonder, K., Stamm, P., Thornton, P., Popovich, N., (2011). A critical appraisal of and recommendations for faculty development. American Journal of Pharmaceutical Education, 75(6):122. Retrieved from: https:/www.ncbi.nlm.nih.gov/pmc/articles/ PMC3175674/

Holt, D., Palmer, D. \& Challis, D. (2011). Changing perspectives: teaching and learning centres' strategic contributions to academic development in Australian higher education. International Journal for Academic Development, 16:1, 5-17.

Institute of Medicine (US) Committee on Assessing the System for Protecting Human Research Subjects. (2001). Preserving public trust: Accreditation and human research Participant protection programs. Washington (DC): National Academies Press. Retrieved from: https://www.ncbi.nlm.nih.gov/books/NBK 43599/ doi: 10.17226/10085 
Kenny, N., Watson, G., \& Watton, C. (2014). Exploring the context of Canadian graduate student teaching certificates in university teaching. Canadian Journal of Higher Education, 44(3), 1-19.

Korpan, C., Sheffield, S., \& Verwood, R. (2015). Teaching assistant competencies in Canada: Building a framework for practice together. Collected Essays in Learning \& Teaching, 8, Society for Teaching and Learning in Higher Education.

Lindberg-Sand, A. \& Sonesson, A. (2008). Compulsory higher education teacher training in Sweden: develop of a national standards framework based in the scholarship of teaching and learning. Tertiary Education and Management 14(2), 123-139.

Martensson, K., Roxa, T. \& Olsson, T. (2011). Developing a quality culture through the Scholarship of Teaching and Learning. Higher Education Research \& Development 30(1), 51-62.

Patton, M. (2002). Qualitative research and evaluation methods (3rd Ed).Thousand Oaks, California: Sage Publications, Inc.

University Teaching Program. (n.d.). Retrieved from http://tlc.cbu.ca/node/284

\section{Biographies}

Celia Popovic, is Director of the Teaching Commons at York University, and is the current Chair of the EDC accreditation committee

Cynthia Korpan is Manager of Professional Development Programs at the University of Victoria.

Alison Jeppesen is a Learning Designer in the Centre for Teaching and Learning, Red Deer College.

Suzanne Le-May Sheffield, Director, Centre for Learning and Teaching, Dalhousie University

Mark Wyers is an Educational Developer at Western University

Mandy Frake-Mistak is an Educational Developer at York University and the incoming chair of the EDC accreditation committee. 